Journal of Bangladesh Academy of Sciences, Vol. 36, No. 2, 177-186, 2012

\title{
EFFECTS OF ADDITIONAL AMOUNT OF CARBON MICRO-COILS ON THE ELECTRICAL PROPERTIES OF CARBON MICRO-COILS COMPOSITE SHEET AS A TACTILE SENSOR
}

\author{
MEHERUN NESSA* AND S. MOTOJIMA \\ Department of Applied Chemistry, Faculty of Engineering, Gifu University, \\ Gifu 501-1193, Japan
}

\begin{abstract}
The morphology and electrical properties, tactile sensing properties of carbon micro-coils (CMC) composite sheet were examined. Frequency dependence of electrical parameters; inductance $(L)$, capacitance $(C)$ and impedance $(Z)$ were measured on single and double-helix composite sheets. It was found that these parameters of carbon micro-coils/polysilicone composites extensively changed with the additional amount of CMC with polysilicone resine. It was also observed that the higher additional amount $(0-10 \mathrm{wt} \%)$ of CMC is appropriate for high sensitivity as a tactile sensor.
\end{abstract}

Key words: Carbon micro-coils, Electrical parameters, Tactile sensor

\section{INTRODUCTION}

Carbon micro-coils (CMC) with 3D-helical/spiral structure with micro- to nanometer order dimensions have been attracting attention in biotechnology and nanotechnology. But materials with 3D-helical/spiral structure with micro- to nanometer order dimensions have not been commercially available. Motojima et al. (2003) have prepared regularly coiled carbon fibers (carbon coils) with 3D-helical/spiral structures with high coil yield (Motojima and Chen 2004). The CMCs are expected to have many unique characteristics, such as good chiral conductivity, high surface area (Chen et al. 1999), very high superelastic property (Chen et al. 2002), very high interaction ability with electromagnetic waves and many potential applications such as tunable micro-devices/sensors, electromagnetic absorbers, energy changing materials, hydrogen absorbers, chiral catalysts, activators of organisms, etc. (Fujii et al. 2002, Furuta et al. 2004, Kato et al. 2003, Varadan et al. 1994, Guerin et al. 1992, Motojima et al. 2003, Motojima et al. 2003). These excellent characteristics are mainly affected by the special chiral/coiling morphology and the micro- to nanometer ordered dimensions. Many researchers have been focused on the preparation of CMC and found regularly micro-coiled carbon fibers with single and double helix and chiral conformation could be obtained by the nickel-

*Corresponding author: <meherun69@yahoo.com>.

Department of Physics, Jagannath University, Dhaka-1100. 
catalyzed pyrolysis of acetylene containing a small amount of sulfur or phosphorus impurity, and also reported the morphologies, growth mechanism and some properties of the products since 1990. For example, was examined the electrical parameters; inductance $(\mathrm{L})$, capacitance $(\mathrm{C})$ and resistance $(\mathrm{R})$ of the $\mathrm{CMC} /$ polysilicone composite sheets at $200 \mathrm{kHz}$ and $10 \mathrm{~V}$, and reported that the CMC/polysilicone composite sheets have high elasticity and high sensitivity against various stimulations, and have potential applications to tactile sensor elements, because that the conformation of $\mathrm{CMC} /$ polysilicone composite sheets resemble to that of a human hand. Tactile sensor usually refers to a transducer that is sensitive to touch, force or pressure. Recently, the electric and dielectric properties of as-grown single and double helix composite CMC were studied and observed that electrical and dielectric properties depend on the frequency and the thickness of the composite (Nessa and Motojima 2006).

Despite a lot of research, how amount of CMC addition show high sensitivity is still controversial. In this work, the effect of addition of different amount of CMC on the frequency dependent of electrical properties and tactile sensing properties are discussed.

\section{MATERIALS AND METHODS}

Preparation and morphology of carbon micro-coils: The chemical vapor deposition (CVD) process was used for the preparation of CMC (Fig. 1). Catalyst (powder or thin films) supported graphite plate was used as the substrate, and was set in the horizontal reaction tube (quartz, $1000 \mathrm{~mm}$ length and $100 \mathrm{~mm}$ i.d.). Acetylene was used as a carbon source and $\mathrm{Ni}$ or stainless steel (SUS 304) fine powder was used as a catalyst. The reaction tube was heated at $700-780^{\circ} \mathrm{C}$ for Ni catalyst and $740^{\circ} \mathrm{C}$ for SUS 304 catalyst from the outside by an electric heater. A source gas mixture of acetylene, hydrogen, hydrogen sulfide and nitrogen was vertically introduced into the reaction tube through the upper gas inlet and exhausted through the lower gas outlet. The gas flow rates of $\mathrm{C}_{2} \mathrm{H}_{2}$, $\mathrm{H}_{2}, \mathrm{H}_{2} \mathrm{~S}$ and $\mathrm{N}_{2}$ were fixed at 840,3500, 150, $600 \mathrm{sccm}$ for $\mathrm{Ni}$ catalyst and 300, 1000, 120 and $500 \mathrm{sccm}$ for SUS 304 catalyst, respectively. The pressure within the reaction tube was atmospheric. High-resolution field effect scanning electron microscope (TOPCON, ABT-150F, Japan) was employed to examine their morphologies and microstructures. The CMC was pulverized and sieving to obtain the composite sample of a coil length below $90 \mu \mathrm{m}$.

Preparation of CMC/polysilicone composite: To obtain a CMC/polysilicone composite sheet, the pulverized $\mathrm{CMC}$ was uniformly mixed with polysilicone resine (Shinetsu Chemicals, KE-103) by different wt $\%$ addition $(0.1,0.5,1,5$ and 10) using a centrifugal conditioning mixer (Shinky, AR-100) and molded in aluminum mould of $10 \times 10 \times 0.1 \mathrm{~mm}^{3}$. The CMC sheet sample with thickness of $0.1 \mathrm{~mm}$ was prepared. 


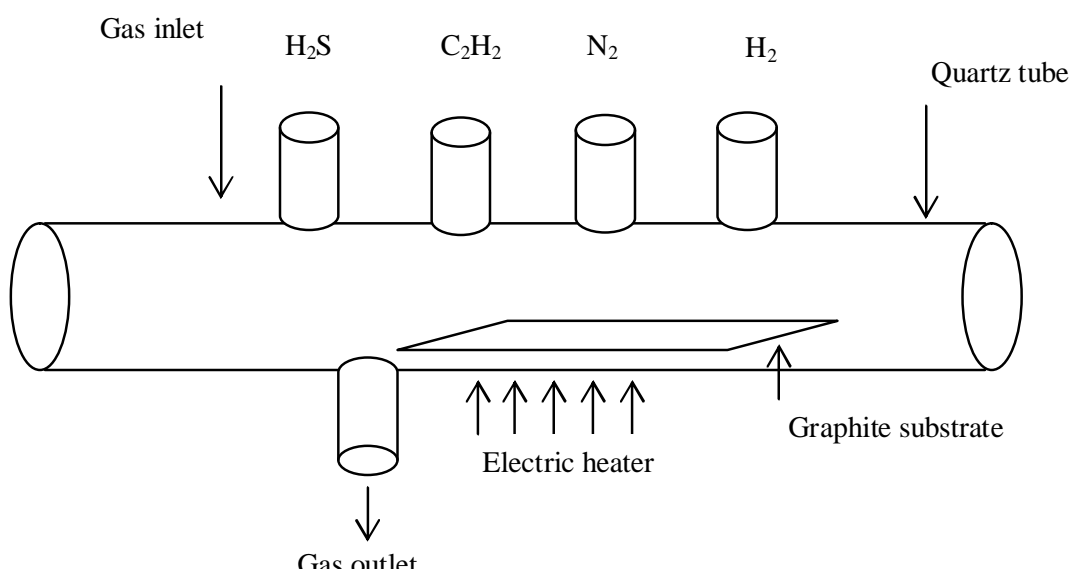

Fig. 1. Schematic diagram of the chemical vapor deposition apparatus.

Measurements of electrical parameters $(L, C, Z)$ : The electrical parameters $(\mathrm{L}, \mathrm{C}, \mathrm{Z})$ of the $\mathrm{CMC} /$ polysilicone composite sheets were measured using an impedance analyzer (Agilent, LCR meter 4294A) in the frequency range from $40 \mathrm{~Hz}$ to $25 \mathrm{MHz}$ where the applied voltage was $0.5 \mathrm{~V}$. The sheet was placed between two vertical parallel electrodes. The used equivalent circuit is shown in Fig. 2.

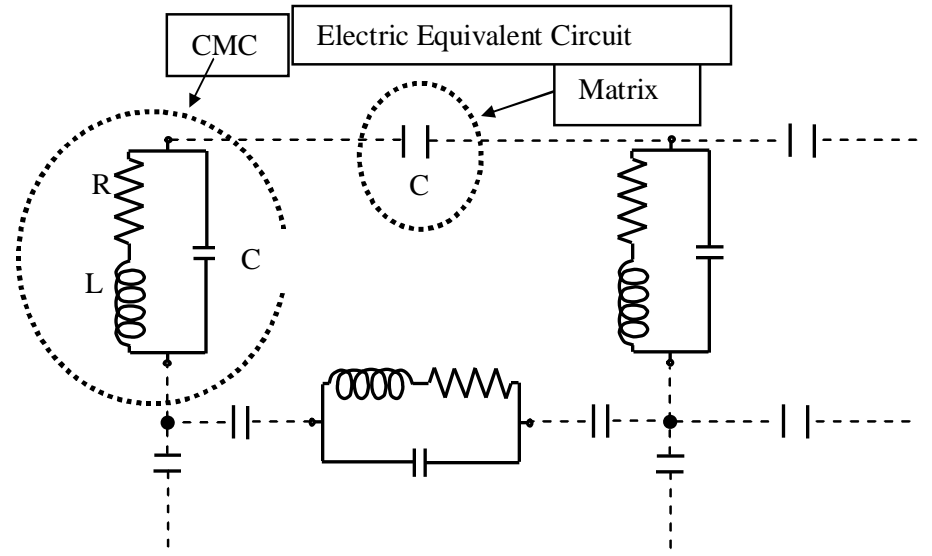

Fig. 2. Equivalent circuit used in the measurement.

Measurement of tactile sensing property: The changes of electrical parameters; L, C and $\mathrm{R}$, of the composite sheets (sensor elements) under applying pressure (static load) were measured using an impedance analyzer (Agilent, 4294A). The load (200 mgf) was applied by a weight for about $120 \mathrm{~s}$ on the surface of sensor elements and signal changes were measured. The sensor element was placed on the multi-electrode, which was connected to the impedance analyzer. 


\section{RESULTS AND DISCUSSION}

In this experimental condition, the obtained CMC exhibited an interesting 3Dhelical/spiral structure with a constant coil diameter of $1-10 \mu \mathrm{m}$ as shown in Fig. 3. Using Ni fine powder, the obtained CMC was generally very densely coiled double-helix forms as shown in Fig. 3(c) and (d). The double-helix CMC have no coil gap through a coil length, and very thin pyrolytic carbon layers of $2-20 \mathrm{~nm}$ thick deposited on the surface of the fiber, from which coil is formed. Accordingly, the double helix coils have a thin tube-like pore with a diameter of $0.2-1 \mu \mathrm{m}$ in the central part of the coils through the coil axis. On the other hand, using SUS 304 catalyst, the obtained CMC have generally single-helix formed with large coil gap of $0.2-5 \mu \mathrm{m}$ and have higher elasticity than that of double helix CMC (Fig. 3(a) and (b).
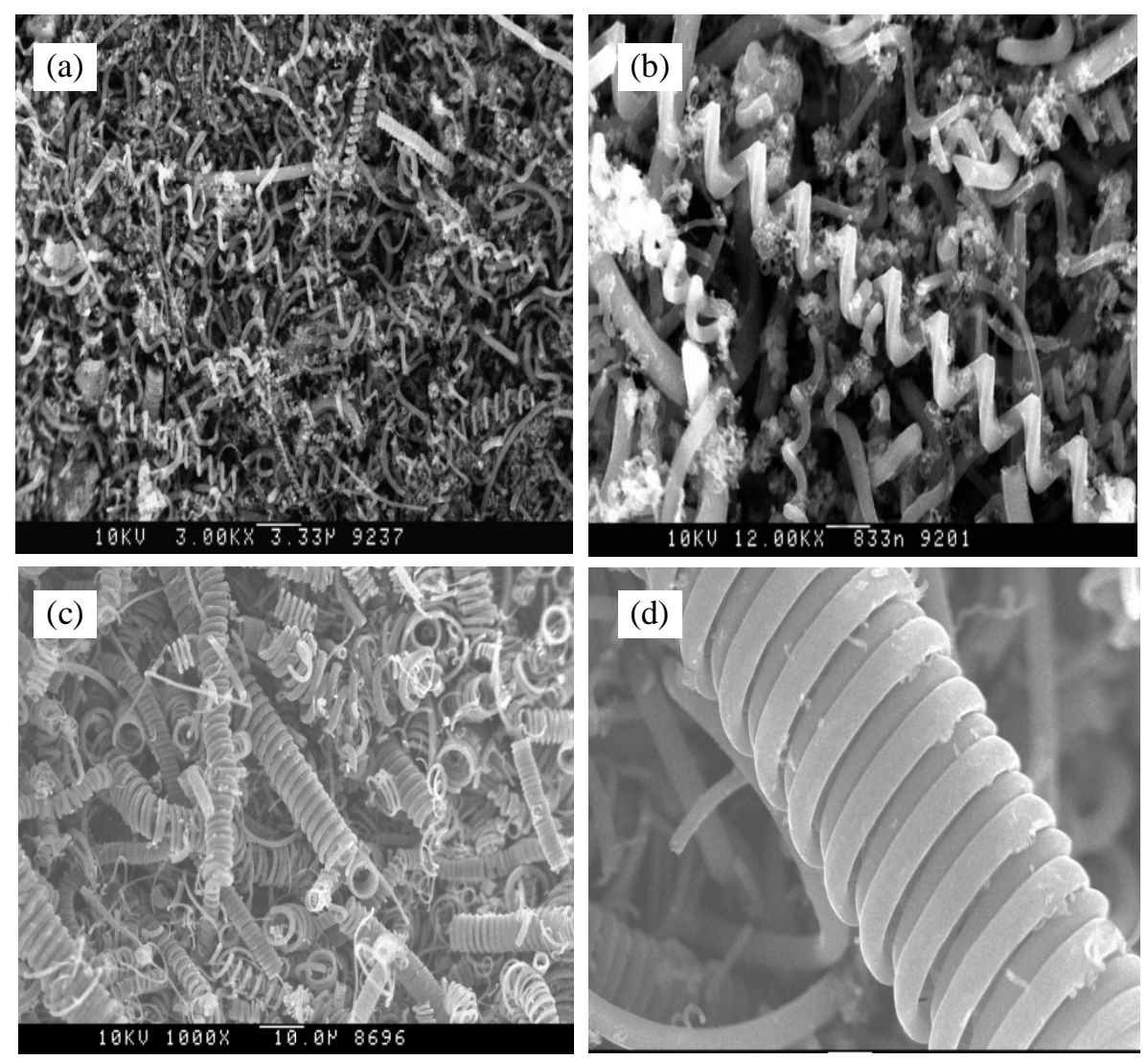

Fig. 3. SEM images of representative carbon micro-coils of (a, b) single helix and (c, d) double helix.

Fig. 4 shows the effect of $\mathrm{CMC}$ addition with polysilicone on the frequency dependence of $\mathrm{L}$ of the composite sheet. The $\mathrm{L}$ of single-helix increases with increasing frequency in the lower frequency region up to $1 \mathrm{kHz}$ and then attain a constant value (Fig. 4a). Higher is the CMC addition larger is the L. The similar dependence is observed 
for a double-helix composite sheet (Fig. 4b). The $\mathrm{L}$ of composite sheet is negative which has no basic meaning (Fig. 4) because L depends on the geometrical factors. But the most obvious property of CMC is their traditional solenoid geometry (Fig. 3). The solenoid geometry provides a sufficient field area and prevents the possibility of current flow constraints that occur in the traditional square spiral micro-scale inductor (Salles et al. 2004). The total L of the CMC sheet can be determined by sum of the self and mutual inductances of each segment given in equ. (i)

$$
\mathrm{L}_{\mathrm{t}}=\sum \mathrm{L}_{\mathrm{s}}+\mathrm{L}_{\mathrm{m}} \quad \text { (i) }
$$

where $\mathrm{L}_{\mathrm{s}}$ and $\mathrm{L}_{\mathrm{m}}$ are the self and mutual inductance, respectively. The mutual inductance might be positive or negative. If negative and higher than self-inductance, then total inductance will be negative. From the experimental result it may be assumed that mutual inductance is negative and so on. The magnitude of inductance was repeatedly observed and was found to be of the $10^{6}$ order. It is well known that the $\mathrm{L}$ depends on the number of coil turns (for solenoid geometry, $L=\mu \mathrm{N}^{2} \mathrm{~A} / \mathrm{l}$ where $\mathrm{N}$ is the number of turns) (Tewari 1995). It may due to the coiling morphology of CMC.

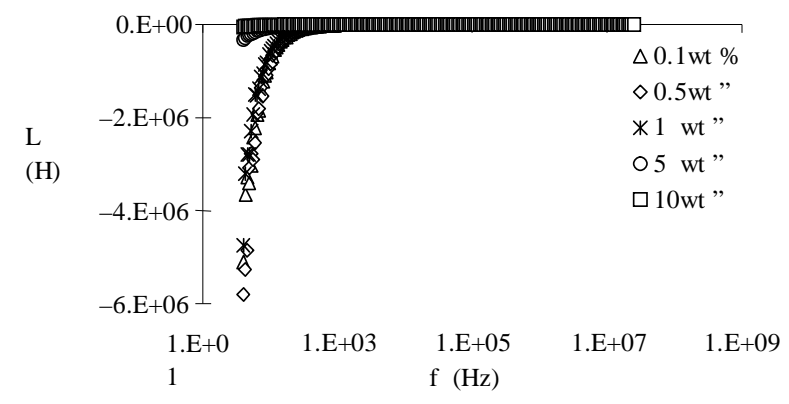

(a)

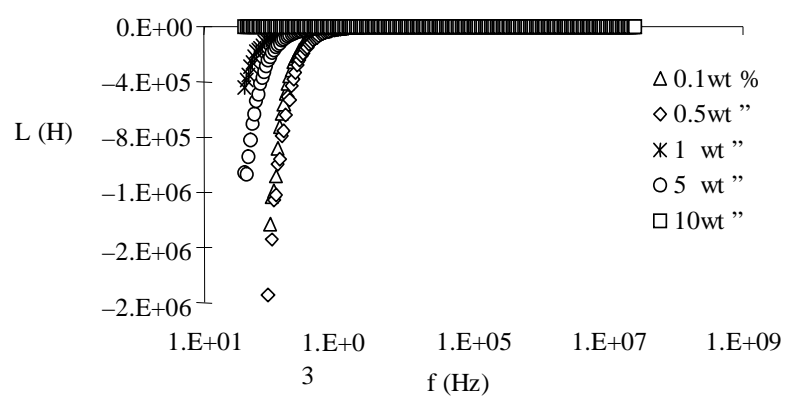

(b)

Fig. 4. Variation of inductance (L) with frequency for the composite sheets of (a) single helix CMC and (b) double helix CMC. Additional amount of CMC: $(\Delta) 0.1 \mathrm{wt} \% ;(\diamond) 0.5 \mathrm{wt} \%$; (Ж) $1 \mathrm{wt} \%$; (O) $5 \mathrm{wt} \%$; (口) $10 \mathrm{wt} \%$. 
Fig. 5 shows the effect of frequency on the $\mathrm{C}$ in relation with the additional amount of CMC in the composite. It is observed that the capacitance of double helix-composite sheet decreases with increasing frequency for higher additional amount of CMC (only 10 $\mathrm{wt} \%$ ). On the other hand, it is observed that the $\mathrm{C}$ of the single helix CMC composite sheet decreases with increasing frequency when additional amount of CMC are $5 \mathrm{wt} \%$ and $10 \mathrm{wt} \%$. In lower additional amount of CMC the $\mathrm{C}$ of the composite sheet is constant with frequency. Initially some noise is observed at the frequency range below $10^{3} \mathrm{~Hz}$, probably caused by weak signal of the applied voltage. For both, single-and double-helix, the behaviours are same but magnitudes are different. This may be caused by the structural flexibility of single and double helix CMC.

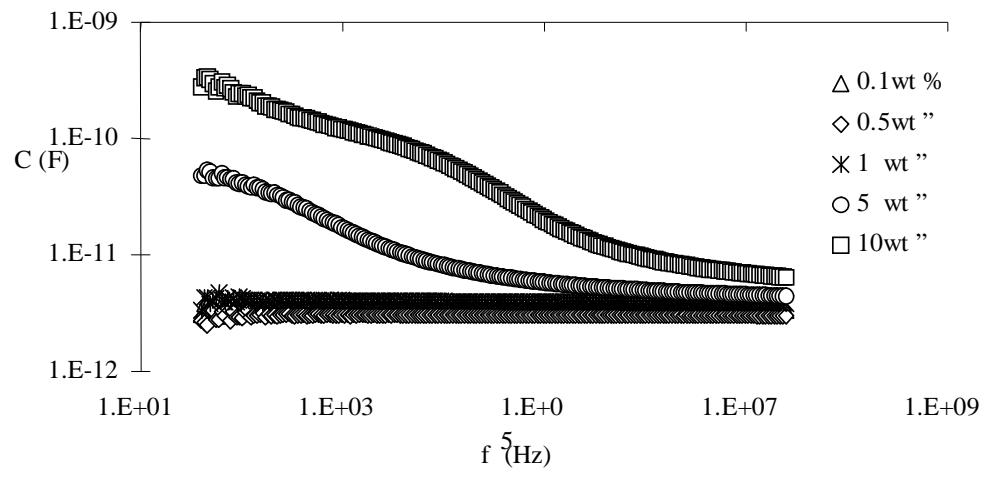

(a)

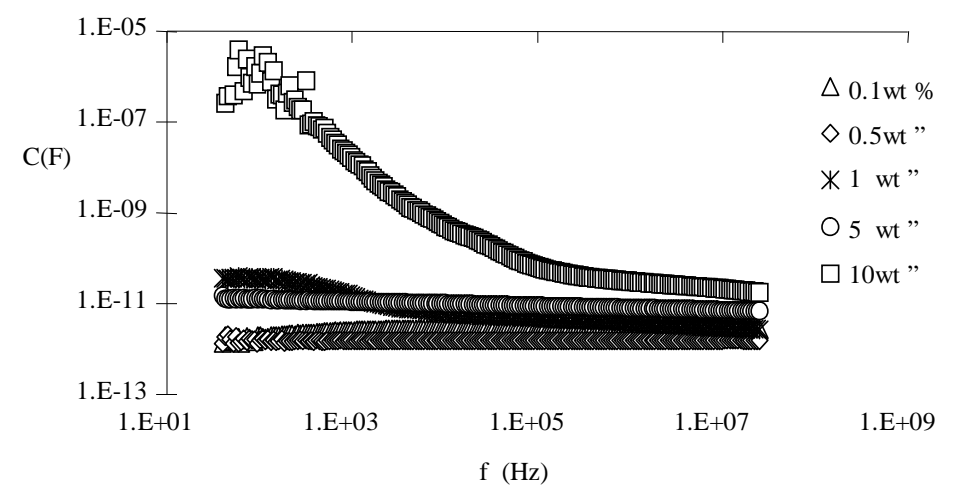

(b)

Fig. 5. Variation of capacitance (C) with frequency for the composite sheets of (a) single helix CMC and (b) double helix CMC. Description of symbols is the same as in Fig. 3. 
Fig. 6(a) and (b) show the effect of CMC addition with polysilicone on the frequency dependence of $Z$ of the composite sheet. The $Z$ decreases with increasing frequency. Higher the CMC additions lower the $Z$ and vise versa. For single and double helix composite sheet, all the results show a similar behavior under the studied conditions.

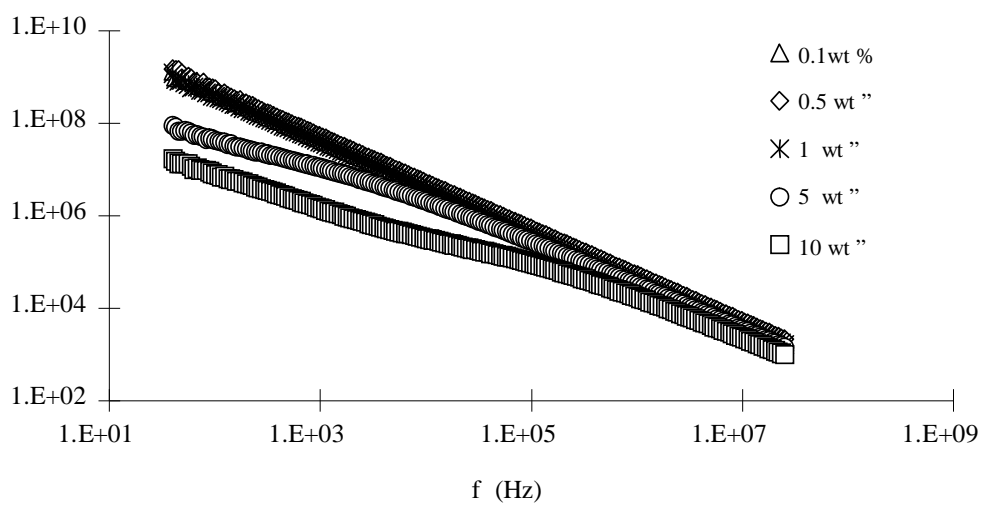

(a)

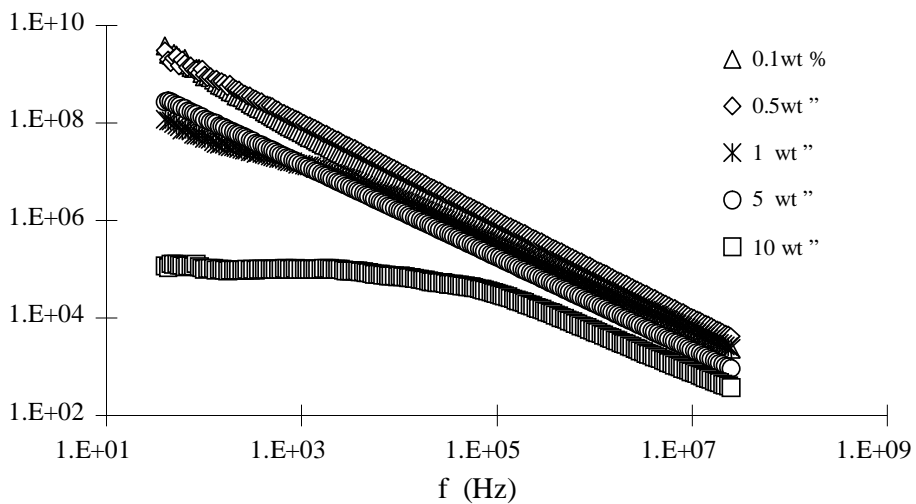

(b)

Fig. 6. Variation of impedance $(\mathrm{Z})$ with frequency for the composite sheets of (a) singlehelix CMC and (b) double-helix CMC. Description of symbols is the same as in Fig. 3.

The sensitivity of CMC as a tactile sensor under the effect of additional amount of CMC with polysilicone resine is discussed. Recently, tactile sensors with very high sensitive abilities can be applicable to medical instruments for safe medical treatments. Accordingly, the CMC sensors have potential application to tactile sensors of various medical instruments such as endoscopes, catheters, manipulation sheets, etc., or as 
artificial skin of humanoid robot, as well as detection sensors of human buried in debris by earthquake, etc.
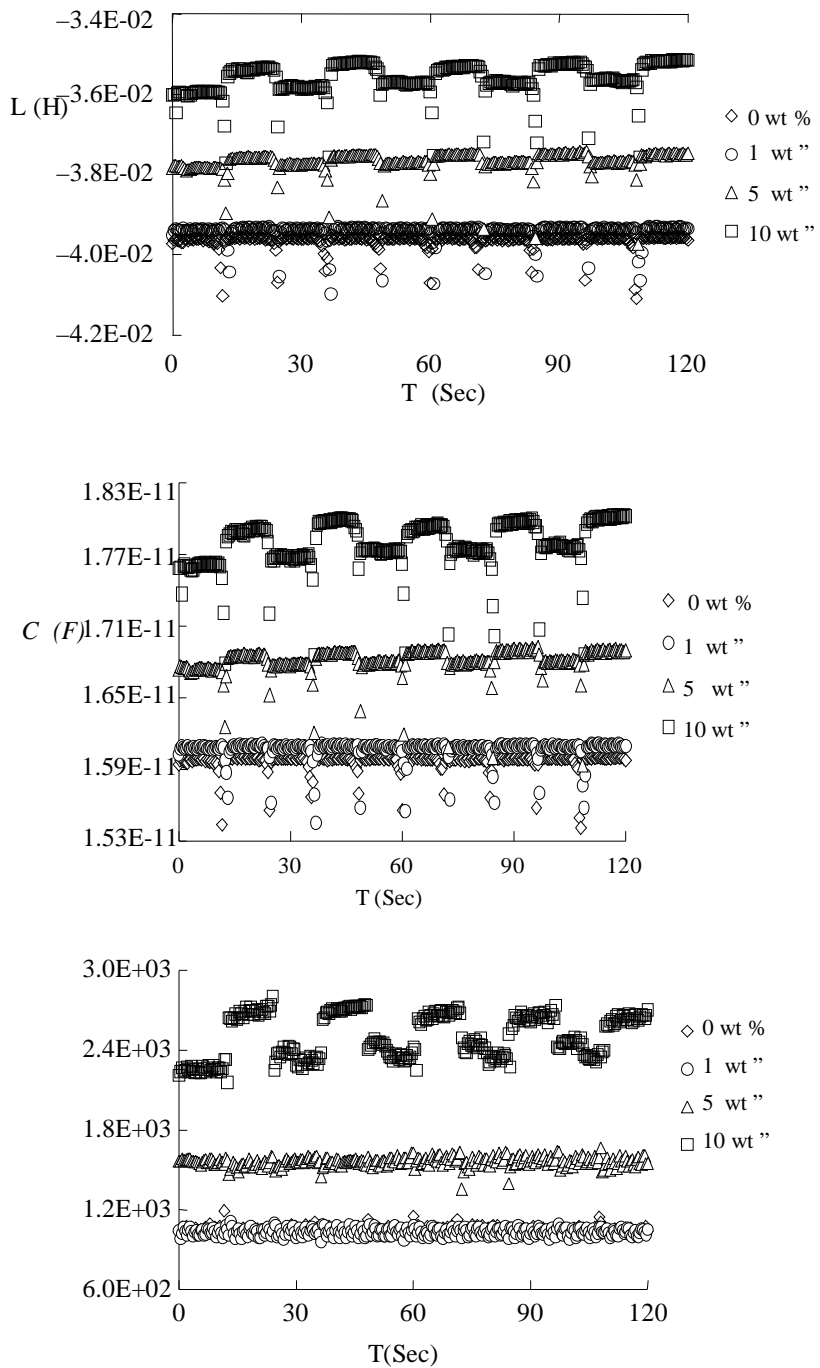

Fig. 7. Variation the tactile sensitivity with time at constant frequency region $(200 \mathrm{kHz})$ against the applied static load (200 mgf) of (a) inductance, (b) capacitance and (c) resistance of double helix CMC composite sheet. Additional amount of CMC: $(\diamond) 0 \mathrm{wt} \%(\mathrm{O}) 1 \mathrm{wt} \%$; ( $\Delta) 5 \mathrm{wt} \%$; $(\square)$ $10 \mathrm{wt} \%$.

From this point of view, it is very important to observe how much CMC addition with polysilicone to make the tactile sensor show high sensitivity and high stability. Using the CMC composite sheets as a tactile sensor element, the high sensitive electrical signals against applied load are observed. In Fig. 7, the sensitivity is higher with the 
higher addition of CMC. For making composite sheet, the higher additional amount of CMCs properly disperses in polysilicone resine. The presence of higher number of coils, there are less mutual effects. Due to high dispersibility and less mutual effects the high sensitive electrical signals against applied load are observed.

\section{CONCLUSION}

The observed characteristics of the electric properties under the additional amount of CMC for single and double helix were nearly same. The frequency dependent of electric parameters are strongly influenced by the additional amount of CMC in the composite sheet. The higher addition of CMC is better than lower addition for detecting high sensitivity of electrical parameters. High tactile sensitivity was also observed when higher amount (10 wt $\%)$ of CMC was added.

\section{REFERENCES}

Chen, X., S. Motojima and H. Iwanaga. 1999. Carbon coatings on carbon micro-coils by pyrolysis of methane and their properties. Carbon 37: 1825-1831.

Chen, X., S. Motojima and H. Iwanaga. 2002. Vapor phase preparation of super-elastic carbon micro-coils. J. Cryst. Growth 237: 1931-1936.

Fujii M., M. Matsui, S. Motojima and Y. Hishikawa. 2002. Magnetoresistance in carbon microcoils annealed at various temperatures. J. Cryst. Growth 237: 239.

Furuta, Y., T. Hashishin, H. Iwanaga, S. motojima and Y. Hishikawa. 2004. Interaction of hydrogen with carbon coils at low temperature. Carbon 42(2): 331-336.

Guerin, F., V. K. Varadan and V.V. Varadan. 1992. Microwave reflection reduction of planar coatings containing ferroelectric ceramic chiral inclusions. J. Wave-Material Interaction 7: 207-224.

Kato, Y., N. Adachi, T. Okuda, T. Yoshida, S. Motojima and Tsuda. 2003. Evaluation of induced electromotive force of a carbon micro-coil Jpn. J. Appl. Phys. 42: 5035-1537.

Motojima, S. and X. Chen. 2004. Review: nanohelical/spiral materials. Encyclopedia of Nanoscience and Nanotechnology. 6: 775-794.

Motojima, S., S. Hoshiya and Y. Hishikawa. 2003. Electromagnetic wave absorption properties of carbon microcoils/PMMA composite beads in W bands. Carbon 41: 2653-2689.

Motojima, S., Y. Noda, S. Hoshiya and Y. Hishikawa. 2003. Electromagnetic wave absorption property of carbon microcoils in 12-110GHz region. J. Appl. Phys. 94: 2653-2689.

Meherun Nessa and S. Motojima. 2006. Electric and di-electric properties of carbon micro-coils (CMC)/polysilicone composite sheets. Material Technology 24(2): 95-103. 
Salles, A., B. Estibals and C. Alonso. 2004. Electro-thermal study of nano-inductors for integrated low power converters. IEEE International Symposium on circuits and systems. Vancouver, Canada. pp. 23-26.

Tewari, K. K. 1995. Electricity and Magnetism with Electronics. 2nd ed., New Delhi, pp. 446.

Varadan, V. V., R. Ro and V.K. Varadan, 1994. Measurement of the Electromagnetic Properties of Chiral Composite Materials in the 8 - $40 \mathrm{GHz}$ range. Radio Science 29: 9-22.

(Received revised manuscript on 8 May, 2012) 